\title{
HLA-DQB1 Polymorphism Determines Incidence, Onset, and Severity of Collagen-induced Arthritis in Transgenic Mice Implications in Human Rheumatoid Arthritis
}

\author{
David S. Bradley, ${ }^{\star}$ Gerald H. Nabozny, ${ }^{\star}$ Shen Cheng, ${ }^{*}$ Paul Zhou, ${ }^{*}$ Marie M. Griffiths,,$\$$ Harvinder S. Luthra, ${ }^{\ddagger}$ \\ and Chella S. David* \\ *Department of Immunology and ${ }^{\ddagger}$ Department of Rheumatology, Mayo Clinic and Medical School, Rochester, Minnesota 55905; and \\ ${ }^{\S}$ Research Service, Veterans Affairs Medical Center, and Department of Medicine, Division of Rheumatology, University of Utah, \\ Salt Lake City, Utah 84132
}

\begin{abstract}
Certain HLA-DR alleles have been associated with predisposition to human rheumatoid arthritis (RA). There is also evidence that certain HLA-DQ alleles may also be important in determining susceptibility to RA. We have previously demonstrated that mice transgenic for HLA-DQ8, a DQ allele associated with susceptibility to RA, develop severe arthritis after type II collagen immunization. To investigate the influence of polymorphic difference at the DQ loci on susceptibility to arthritis, we generated mice transgenic for HLADQ6, an allele associated with a nonsusceptible haplotype. The DQ6 mice were found to be resistant to collagen-induced arthritis. We also assessed the combined effect of an RA-susceptible and an RA nonassociated DQ allele by producing double-transgenic mice expressing DQ6 and DQ8 molecules, representing the more prevalent condition found in humans where heterozygosity at the DQ allele is common. The double-transgenic mice developed moderate CIA when immunized with CII when compared with the severe arthritis observed in DQ8 transgenic mice, much like RA patients bearing both susceptible and nonsusceptible HLA haplotypes. These studies support a role for HLA-DQ polymorphism in human RA. (J. Clin. Invest. 1997. 100:2227-2234.) Key words: autoimmune disease $\cdot$ HLA class II • rheumatoid arthritis $\bullet$ transgenic mice $\bullet$ type II collagen
\end{abstract}

\section{Introduction}

Certain MHC class II alleles are linked to human autoimmune diseases such as RA (1-3), insulin-dependent (type I) diabetes mellitus (2-7), systemic lupus erythematosus $(1,8-11)$, Sjögren's syndrome $(1,10,11)$, multiple sclerosis $(12)$, Grave's dis-

The current addresses of three of the authors are as follows: G.H. Nabozny, Division of Immunological Diseases, Boehringer Ingelheim Pharmaceuticals, Inc., Ridgefield, CT 06877; S. Cheng, DEKALB Poultry Research, Inc., 3100 Sycamore Rd., Dekalb, IL 60115; and P. Zhou, Laboratory of Oral Medicine, National Institute of Dental Research, National Institutes of Health, 9000 Rockville Dr., Bethesda, MD 20892.

Address correspondence to Dr. Chella S. David, Department of Immunology, Mayo Clinic, Rochester, MN 55905. Phone: 507-2848182; FAX: 507-284-1637; E-mail: david.chella@mayo.edu

Received for publication 14 March 1997 and accepted in revised form 22 August 1997.

The Journal of Clinical Investigation

Volume 100, Number 9, November 1997, 2227-2234

http://www.jci.org ease (5-7), and Addison's disease (13). Although the mechanism(s) by which expression of certain MHC class II alleles predispose an individual to a particular autoimmune disease are not known, it is clear that increased susceptibility is associated with the polymorphic regions unique to the predisposing alleles. The polymorphic differences may influence susceptibility during thymic education of $\mathrm{T}$ cells by selection of potentially autoreactive $\mathrm{T}$ cells. Conversely, nonsusceptible class II alleles may either negatively select or fail to positively select autoreactive $\mathrm{T}$ cells, thereby reducing the risk of developing autoimmunity. In the periphery, the unique specificity of a class II molecule derived from a susceptible allele may be able to recognize and present an autoantigenic peptide, stimulating an undeleted group of autoimmune T cells. On the other hand, $\mathrm{T}$ cells directed against a bacterial or viral antigen may crossreact with an autoantigen (14). We have recently proposed that the presentation of self peptides derived from class II molecules may play a role in shaping the $\mathrm{T}$ cell repertoire (15). This mechanism is particularly intriguing in light of evidence that a significant percentage of the naturally processed peptides presented by class II molecules are derived from endogenous class II molecules $(16,17)$.

Human RA is an autoimmune disease in which the association between expression of certain HLA class II alleles and the predisposition to disease has been extensively studied. Expression of certain HLA-DR4 subtypes: DRB1*0401 (Dw4), DRB1*0404/0408 (Dw14), and DRB1*0405 (Dw15) have been linked with susceptibility to RA, while another HLA-DR4 subtype, DRB1*0402 (Dw10), has been shown not to be associated with RA (18-20). In addition, a DR1 subtype, DRB1* 0101 (Dw1), has also been linked to RA (21). Gregersen et al. and Winchester et al. $(22,23)$ observed that each of these DR alleles associated with RA contain significant homology within their third hypervariable regions (HV3), positions 67-74, and thus hypothesized that the presence of this region, termed the shared epitope region, was responsible for the predisposition to RA associated with these alleles. The mechanism by which the shared epitope region is able to predispose an individual to RA is still unclear. Additionally, further analyses of HLA class II associations with RA have shown inconsistencies to this hypothesis, including the association of the DR alleles DRB1* 0301 (Dw3), DRB1*0901 (Dw23), and DRB1*1001 with RA, which encodes different sequences within the shared epitope region (23-26).

Recent studies have suggested that the HLA-DQ molecule may also play a role in susceptibility to autoimmunity. Because of linkage disequilibrium, expression of certain DR and DQ alleles is frequently linked (27). This phenomenon has led to the finding that certain DQ alleles, expressed with previously identified DR alleles, are more closely associated with suscep- 
tibility, or resistance, to Sjögren's syndrome (28), myasthenia gravis (29), and insulin-dependent (type I) diabetes $(30,31)$. Examination of the association of DQ alleles with RA has also suggested a preferential usage of certain alleles. Two studies have reported an increased number of RA patients expressing DQ7 $(32,33)$ that is in linkage disequilibrium with DR4 (22). In addition, analysis of HLA class II linkage in the Asian Indian population has shown that $100 \%$ of RA patients studied expressed the DQ8 allele (34), also in linkage disequilibrium with DR4, compared to one-third of healthy controls.

Type II collagen (CII) ${ }^{1}$ constitutes a major component of hyaline cartilage in the joints (35). As a triple helix with a unique repeat sequence, CII could harbor several sequestered determinants, and thus harbor a potential autoantigen. Studies in RA patients have shown antibody and $\mathrm{T}$ cell activity directed to intact and denatured CII (36-38). Furthermore, injection of heterologous CII into rats, mice, and monkeys results in joint inflammation and pathology with considerable similarity to human RA $(35,39,40)$. Collagen-induced arthritis (CIA) is linked to MHC class II genes, similar to RA (41).

Recent findings by Nabozny et al. (42) using HLA-DQ8 transgenic mice in CIA also support a role for DQ in the predisposition to RA. These mice express DQ8 transgenes in the absence of endogenous murine class II expression, and developed severe polyarthritis after immunization with CII. To determine whether polymorphism within the DQB1 locus determines susceptibility to CIA similar to human RA, we generated transgenic mice expressing HLA-DQ6 (DQA1*0103/ DQB1*0601) gene, which is not associated with RA in humans. Furthermore, since many RA patients are heterozygous at the HLA DQ loci, the influence of the nonsusceptible HLA class II molecules on an autoimmune response has not been well-defined. We generated double-transgenic mice expressing DQ6 and DQ8 molecules to simulate a heterozygous human haplotype.

\section{Methods}

Mice. Mice used in this study were bred within the pathogen-free barrier facility, and were maintained in our clean conventional area of the Mayo Immunogenetics Mouse Colony (Rochester, MN). Mice expressing HLA-DQ6 and HLA-DQ8 (42) transgenes were produced by our transgenic laboratory as previously described (43). In brief, cosmid H11A, containing DQA $1 * 0301$ and DQB $1 * 0302$ genes (44), and cosmid X10A, containing DQB $1 * 0302$, were microinjected into $(\mathrm{CBA} / \mathrm{J} \times \mathrm{B} 10 . \mathrm{M}) \mathrm{F}_{2}$ embryos, resulting in B10.M-DQ8 transgenic mice. Similarly, a 40-kb construct containing DQB1*0601, derived from a cosmid isolate from the AKIBA cell line, was microinjected into $(\mathrm{CBA} / \mathrm{J} \times \mathrm{B} 10 . \mathrm{M}) \mathrm{F}_{2}$ embryos, producing B10.M-DQ6 $\beta$ transgenic mice (45), and a construct containing the DQA1*0103 gene, also derived from the AKIBA cell line, was microinjected into $(\mathrm{CBA} / \mathrm{J} \times \mathrm{B} 10 . \mathrm{M}) \mathrm{F}_{2}$ embryos, resulting in B10.M-DQ6 $\alpha$ transgenic mice. Each strain was bred onto a mouse class II-deficient $(A \beta 0)$ background (46). The DQ6 $\alpha(A \beta 0)$ and DQ6 $\beta(A \beta 0)$ mice were then mated to obtain a DQ6 $\alpha \beta$ strain. The DQ6 $\beta(A \beta 0)$ mice were also mated to the DQ8 $\alpha \beta$ (A $\beta 0)$ mice to generate the DQ6 $\beta / 8 \alpha \beta(\mathrm{A} \beta 0)$ double-transgenic mice. All mice were between 6 and 12 wk of age when experiments were initiated. Both male and female mice were equally represented in each experimental cohort.

1. Abbreviations used in this paper: $\mathrm{AU}$, antibody units; CII, type II collagen; CIA, collagen-induced arthritis; LNC, lymph node cells; PBL, peripheral blood lymphocytes; TCR, T cell receptor.
Flow cytometry. Expression of HLA-DQ and H-2 class II molecules on the surface of peripheral blood lymphocytes (PBLs) was analyzed by flow cytometry. Lymphocytes were isolated from freshly obtained whole blood on a Ficoll-Hypaque gradient, and were washed in phosphate buffered saline containing $1 \%$ BSA and $0.1 \%$ sodium azide. The cells were incubated with $\mathrm{mAb}$ specific for HLADQ $\alpha$ (IVD12; [47]), HLA-DQ6 $\beta$ (L227; [48]), H-2A ${ }_{\alpha}{ }^{\mathrm{b}}$ (7-16.7; [49]), or $\mathrm{H}-2 \mathrm{E}_{\beta}{ }^{\mathrm{b}}(\mathrm{Y}-17 ;[50])$ at $4^{\circ} \mathrm{C}$ for $30 \mathrm{~min}$, washed, and incubated with FITC-conjugated goat $\mathrm{Fab}_{2}{ }_{2}$ fragment specific for mouse IgG (Accurate Chemical \& Science Corp., Westbury, NY) at $4^{\circ} \mathrm{C}$ for $30 \mathrm{~min}$. The $\mathrm{T}$ cell receptor (TCR) V $\beta$ usage of $\mathrm{CD} 4+\mathrm{T}$ cells was determined on PBLs, extensively washed, and incubated for $30 \mathrm{~min}$ with one of

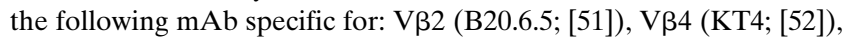

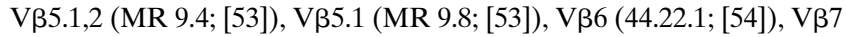
(TR.310; [55]), V $\beta 8.1,2,3$ (F23.1: [56]), V $\beta 8.1,2$ (KJ16-133; [57]), V $\beta 8.2$

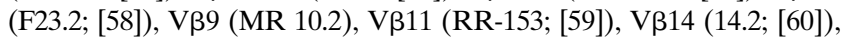
or V $\beta 17$ (KJ23a; [61]). The cells were washed and incubated with FITC-conjugated $\mathrm{Fab}_{2}{ }_{2}$ of anti-rat IgG for $30 \mathrm{~min}$. The cells were washed again and incubated with phycoerytherin-conjugated mouse anti-CD4 mAb for $30 \mathrm{~min}$. All stained cells were fixed in 1\% leukocyte formalin and analyzed using a FACS ${ }^{\circledR}$ vantage flow cytometer (Becton Dickinson, Mountain View, CA).

Assessment of CII-specific T cell proliferation. Mice were primed with $200 \mu \mathrm{g}$ of bovine CII emulsified 1:1 in CFA (Mycobacterium tuberculosis H37 Ra; Difco Laboratories Inc., Detroit, MI), $100 \mu \mathrm{g}$ intradermally at the base of the tail, and $50 \mu \mathrm{g}$ in each of the hind footpads. $10 \mathrm{~d}$ later, the mice were killed, and draining lymph nodes were removed. Lymph node cells (LNCs) were purified and resuspended, $1 \times$ $10^{7}$ cells $/ \mathrm{ml}$, in complete medium (RPMI $1640,5 \%$ heat inactivated horse serum, $25 \mathrm{mM}$ Hepes, $2 \mathrm{mM}$ glutamine, $100 \mathrm{U} / \mathrm{ml}$ penicillin, and $100 \mu \mathrm{g} / \mathrm{ml}$ streptomycin; Gibco Laboratories, Grand Island, NY). $100 \mu \mathrm{l}$ of the LNCs suspension $\left(1 \times 10^{6}\right.$ cells $)$ was added in triplicate to flat-bottomed microtiter plates (Corning Glass Works, Corning, $\mathrm{NY}$ ), and was challenged with $5 \mu \mathrm{g} /$ well heat-denatured bovine CII. Triplicate control wells were also included with LNCs cultured in media alone. The cells were incubated for $2 \mathrm{~d}$ at $37^{\circ} \mathrm{C}$ in $5 \% \mathrm{CO}_{2}$, pulsed with $1.8 \mu \mathrm{Ci}$ of $\left[{ }^{3} \mathrm{H}\right]$ thymidine, and incubated for an additional $18 \mathrm{~h}$. The cells were harvested, and $\left[{ }^{3} \mathrm{H}\right]$ thymidine uptake was measured as cpm in a liquid scintillation counter (Beckman Instruments, Palo Alto, CA). To compare proliferative responses between strains of mice with different innate background cpm, proliferation was standardized to a stimulation index, and calculated as follows: mean cpm of triplicate cultures with denature bovine $\mathrm{CII} \div$ mean cpm of triplicate cultures with medium alone. Only stimulation index values of greater than 2.5 were considered to be evidence of a significant proliferative response.

For blocking studies, mAb specific for HLA-DQ (IVD12), HLADQ6 $\beta$ (L227), H-2 $\mathrm{A}_{\alpha}^{\mathrm{b}}$ (7-17.7), $\mathrm{H}-2 \mathrm{E}_{\beta}{ }^{\mathrm{b}}$ (Y-17), CD4 (GK1.5), and CD8 (53.7.72), or an irrelevant isotype-matched $\mathrm{mAb}$ specific for HLA-A, -B, -C (MB40.5), was added (20 $\mu$ l of culture supernatant/ well) to cultures of LNCs stimulated with bovine CII. The effect of blocking was reported as the percent of inhibition: $1-(\Delta \mathrm{cpm}$ of cultures + experimental $\mathrm{mAb}) \div(\Delta$ cpm of cultures + irrelevant control $\mathrm{mAb}) \times 100$.

Induction of CIA. CIA was induced as previously described (42). In brief, lyophilized bovine CII (62) was reconstituted $(2 \mathrm{mg} / \mathrm{ml})$ in $0.01 \mathrm{~N}$ acetic acid and emulsified, 1:1, in CFA. Mice were immunized with $100 \mu \mathrm{l}$ of the bovine CII emulsion intradermally at the base of the tail, and then boosted $28 \mathrm{~d}$ later with $100 \mu \mathrm{g}$ of bovine CII emulsified in incomplete Freund's Adjuvant. Experimental mice were monitored at least three times a week for $12 \mathrm{wk}$ after immunization, for the development of clinical arthritis. The severity of arthritis was scored for each limb as previously described (41): 0, normal, no inflammation; +1 , swelling of digits; +2 , severe swelling of foot, ankle, and/or joint deformity; or +3 , ankylosis of the ankle joint. Thus, each mouse had a possible score of 0 to 12 .

Anti CII antibody analysis. Anti-bovine and anti-mouse CII IgG levels were measured by ELISA (63) in sera obtained 35 and $84 \mathrm{~d}$ af- 
ter bovine CII immunization. Microtiter plates were coated with either bovine or mouse CII, $6 \mu \mathrm{g} /$ well, in $\mathrm{KPO}_{4}$ buffer, $\mathrm{pH}$ 7.6, and were incubated overnight at $4^{\circ} \mathrm{C}$. The plates were washed with PBSTween (PBS $+0.5 \%$ Tween $20+0.2 \mathrm{M} \mathrm{NaCl}$ ) and blocked with $1 \%$ BSA in PBS-Tween. Sample sera were diluted serially, fourfold from 1:100 to $1: 65,000$, added to the wells in duplicate, and incubated overnight at $4^{\circ} \mathrm{C}$. A series of dilutions of a high titer anti-CII positive serum were run in parallel with all assays. The plates were washed with PBS-Tween, peroxidase-conjugated goat anti-mouse IgG (Organon Teknika Corp., West Chester, PA) was added, and the plates were incubated overnight at $4^{\circ} \mathrm{C}$. After washing plates with PBS-Tween, $\mathrm{O}$-phenlenediamine was added, and the colorimetric change was determined at $410 \mathrm{~nm}$. Levels of anti-CII antibody are expressed as antibody units (AU), calculated by comparison with the optical density obtained from high titer standard sera, arbitrarily determined to equal $100 \mathrm{AU} / \mathrm{ml}$.

To determine the CII specificity of the anti-bovine CII antibodies, a similar ELISA technique (63) was performed with plates coated with one of the following cyanogen bromide (CB) fragments of bovine CII: CB8, CB9/7, CB10, CB11, or CB12. The level of anti-CII IgG specific for a particular $\mathrm{CB}$ fragment was expressed as percentage of the total CII antibody response: $(1-[\mathrm{OD}$ of the $\mathrm{CB}$ specific $\mathrm{IgG}] \div$ [OD of total anti-bovine CII IgG] $) \times 100$.

Statistical analysis. Statistical comparisons of the arithmetic means of the arthritic severity, onset of clinical arthritis, and antibody levels were determined by the Student's $t$ test.

\section{Results}

Generation of transgenic $H L A-D Q 6 \alpha \beta(A \beta 0)$ and double transgenic $H L A-D Q 6 \beta / 8 \alpha \beta(A \beta 0)$ mice. We generated mice transgenic for HLA-DQ6, an allele not associated with predisposition to RA in humans, to investigate the influence of polymorphism in the HLA-DQ loci on susceptibility to arthritis. As outlined in Fig. 1, DQ6 $\alpha$ (A $\beta 0)$ and DQ6 $\beta$ (A $\beta 0)$ mice were mated, and offspring were screened for the presence of DQ6 $\alpha$ and $\beta$ transgenes by PCR of peripheral blood, and the expression of DQ6 molecules by flow cytometeric analyses of PBLs. Only mice bearing both DQ6 $\alpha$ and $\beta$ genes expressed DQ6 molecules on their PBLs $(\sim 37 \%)$ (Table I). The parental DQ6 $\alpha$ and DQ6 $\beta$ strains are capable of expressing $\mathrm{H}-2 \mathrm{~A}_{\alpha}{ }^{\mathrm{b}}$ and $\mathrm{H}-2 \mathrm{E}_{\beta}{ }^{\mathrm{b}}$ chains within the cytoplasm (46), and to insure that the DQ6 molecules detected in the DQ6 $\alpha \beta$ mice did not result from the formation of hybrid molecules of endogenous $\mathrm{H}-2$ class II chains with the corresponding DQ chain such as $\mathrm{A}_{\alpha}{ }^{\mathrm{b}}-\mathrm{DQ} 6_{\beta}$ or DQ6 $6_{\alpha}-\mathrm{E}_{\beta}{ }^{\mathrm{b}}$, DQ6 PBLs were screened for the surface expression $\mathrm{H}-2 \mathrm{~A}_{\alpha}{ }^{\mathrm{b}}$ and $\mathrm{H}-2 \mathrm{E}_{\beta}{ }^{\mathrm{b}}$ chains. As shown in Table $\mathrm{I}$, neither $\mathrm{H}-2 \mathrm{~A}_{\alpha}{ }^{\mathrm{b}}$ nor $\mathrm{H}-2 \mathrm{E}_{\beta}{ }^{\mathrm{b}}$ molecules were undetected on DQ6 $\alpha \beta$ PBLs. Thus, DQ6 $\alpha \beta$ mice express DQ6 molecules on
Table I. Representative Percentages of PBLs Expressing MHC Class II Molecules in HLA-DQ Transgenic Mice

\begin{tabular}{lcccc}
\hline \multicolumn{1}{c}{ Strain } & $\begin{array}{c}\% \mathrm{DQ} \alpha \\
(\text { IVD12) }\end{array}$ & $\begin{array}{c}\% \mathrm{DQ6 \beta} \\
(\mathrm{L} 227)\end{array}$ & $\begin{array}{c}\% \mathrm{H}-2 \mathrm{~A} \alpha^{\mathrm{b}} \\
(7-16.7)\end{array}$ & $\begin{array}{c}\% \mathrm{H}-2 \mathrm{E} \beta^{\mathrm{b}} \\
(\mathrm{Y} 17)\end{array}$ \\
\hline HLA-DQ6 $\alpha \beta$ & 37.2 & 52.3 & $-\ddagger$ & - \\
HLA-DQ8 $\alpha \beta$ & 34.5 & 14.8 & - & - \\
HLA-DQ6 $\beta / 8 \alpha \beta$ & 39.1 & 47.8 & - & - \\
$\mathrm{H}-2 \mathrm{~A} \beta 0$ & - & - & - & - \\
B10 $\left(\mathrm{H}-2^{\mathrm{b}}\right)$ & - & - & 52.6 & - \\
B10.E $\alpha^{\mathrm{k}}\left(\mathrm{H}-2 \mathrm{~A}^{\mathrm{b}} / \mathrm{E} \alpha^{\mathrm{k}} \mathrm{E} \beta^{\mathrm{b}}\right)$ & - & - & 38.6 & 29.8 \\
& & & & \\
\hline
\end{tabular}

LNCs were purified and assessed for the surface expression of HLADQ and H-2 molecules by flow cytometry as described in Methods. The values displayed are the result of pooled lymph node cells from two mice/strain, and are representative of numerous analyses. *mAb used for primary staining. ${ }^{\ddagger}$ " " indicates that the percentage of cells detected were equal to, or less than, background staining.

the surface of their PBLs in the absence of endogenous mouse class II surface expression.

A second objective of these studies was to examine the influence of simultaneous expression of two DQ alleles, one associated with the predisposition to RA, and one associated with resistance to RA. To this end, DQ6 $\beta$ (A $\beta 0)$ mice were mated with DQ $8 \alpha \beta$ (A $\beta 0)$ mice (42) as depicted in Fig. 1. The resulting litters were screened by PCR for the presence of DQ6 $\beta, D Q 8 \alpha$, and DQ8 $\beta$ genes, and by flow cytometry for expression of DQ6 and DQ8 molecules. Mice positive for the products of both transgenes were then intercrossed to develop the HLA-DQ6 $\beta / 8 \alpha \beta$ (A $\beta 0)$ strain (DQ6 $\beta / 8 \alpha \beta)$. Representative surface expression of DQ molecules on DQ6 $\beta 8 \alpha \beta$ PBLs is shown in Table I. Approximately $40 \%$ of the PBLs from DQ6 $/$ $8 \alpha \beta$ mice express DQ molecules, comparable to DQ expression on DQ6 $\alpha \beta$ and DQ8 $\alpha \beta$ PBLs. This result is also equivalent to I-A ${ }^{b}$ expression detected on B10.E $\alpha \mathrm{K}$ PBLs. The DQ6 molecule was detected on $48 \%$ of PBLs from DQ6 $\beta / 8 \alpha \beta$ mice, expression equivalent to DQ6 $\alpha \beta$ transgenic mice. Analysis of DQ6-specific surface expression was not quantitative, and therefore, levels of total DQ and DQ6 expression cannot be compared. Neither $\mathrm{H}-2 \mathrm{~A} \alpha^{\mathrm{b}}$ nor $\mathrm{H}-2 \mathrm{E} \beta^{\mathrm{b}}$ molecules were detected on DQ6 $\beta / 8 \alpha \beta$ PBLs (Table I), indicating the lack of both endogenous class II expression and the formation of hybrid molecules.

Each of the DQ transgenic strains expressed a small popu-

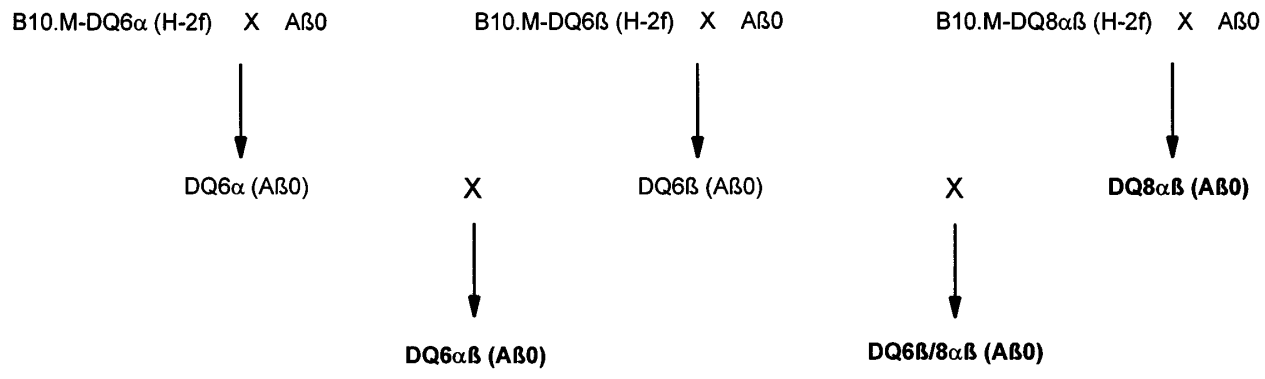

Figure 1. Schematic diagram of the breeding strategy to used derive HLA-DQ6 $\alpha \beta$ and HLA-DQ6 $\beta /$ $8 \alpha \beta$ mice. The individual DQ transgenes were originally introduced into the B10.M $\left(\mathrm{H}-2^{\mathrm{f}}\right)$ background. These B10.M-DQ transgene mice were then bred on to a H-2 class IIdeficient background as depicted. The presence of the transgene was detected in peripheral blood by PCR using oligonucleotide primers specific for the designated DQ chain. The expression of DQ molecules and the absence of endogenous H-2 class II was determined by flow cytometry of PBLs, using the mAbs identified in Methods. The three strains of importance to these studies are distinguished in bold lettering. 


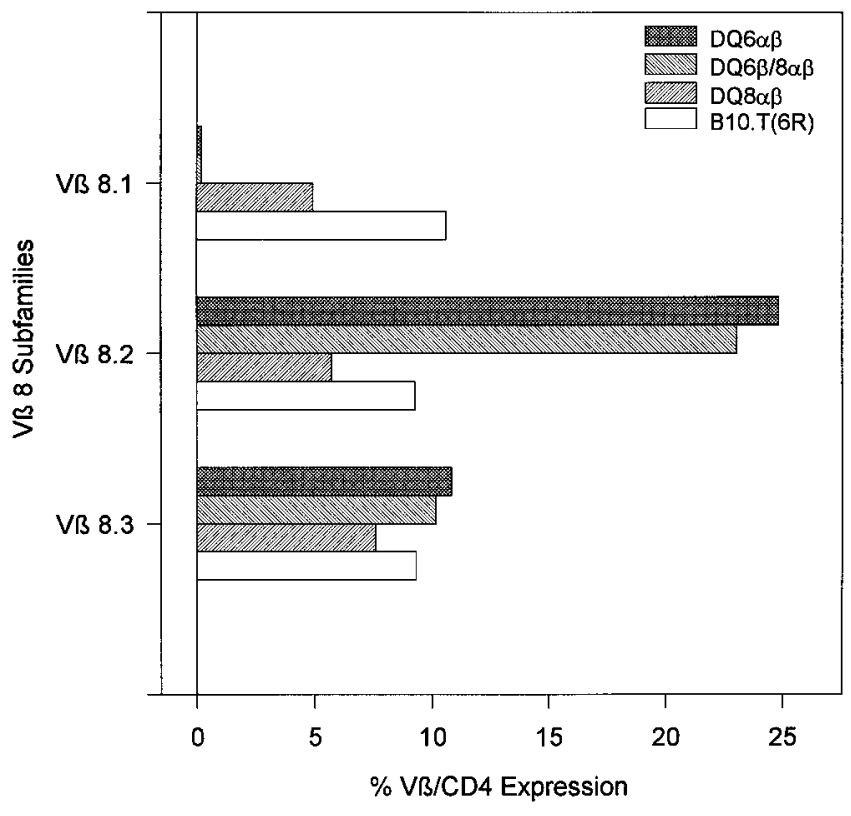

Figure 2. The TCR V $\beta 8$ usage in HLA-DQ6 $\alpha \beta$ and HLA-DQ6 $\beta / 8 \alpha \beta$ mice. PBLs of three DQ6 $\alpha \beta$, DQ6 $\beta / 8 \alpha \beta$, DQ8 $\alpha \beta$, and B10.T(6R) mice were assessed individually for TCR V $\beta 8$ expression by flow cytometry. The expression of individual V8 subfamilies was determined subtractively from $\mathrm{V} \beta$ expression determined by anti-V $\beta 8.1,2,3$

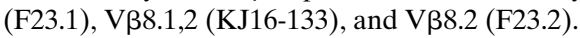

lation of CD4+ PBLs, 5.0, 6.2, and 9.3\% in DQ6 $\alpha \beta$, DQ6 $\beta /$ $8 \alpha \beta$, and DQ8 $\alpha \beta$ mice, respectively, compared with $12.4 \%$ in $\mathrm{B} 10 . \mathrm{T}(6 \mathrm{R})$ mice. Although there was a considerable difference between the size of CD4+ populations detected in DQ6 $\alpha \beta$ and

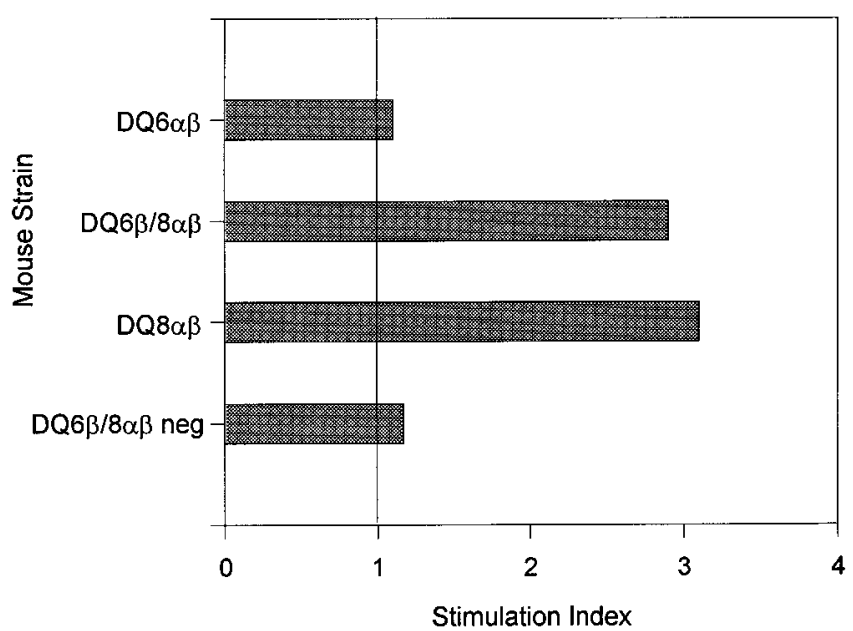

Figure 3. CII-specific proliferative response of HLA-DQ6 $\alpha \beta$ and HLA-DQ6 $\beta / 8 \alpha \beta$ mice. Purified LNCs of bovine CII-primed mice, pooled from three DQ6 $\alpha \beta$, DQ6 $\beta / 8 \alpha \beta$, DQ8 $\alpha \beta$, or DQ6 $\beta / 8 \alpha \beta$ negative mice, were challenged with bovine CII, and proliferation was determined by $\left[{ }^{3} \mathrm{H}\right]$ thymidine incorporation as described in Methods. The results are displayed as a standardized stimulation index to allow for comparison of proliferation between LNCs of different strains with differing background proliferation, and are representative of three separate assays (only proliferative responses of a stimulation index $\geq 2.5$ were considered significant.)
DQ8 $\alpha \beta$ mice, the DQ6 $\alpha \beta$ mice do contain sufficient numbers of CD4+ cells to mount CD4-mediated immune responses directed against various antigens, including house dust mite, ragweed, and rye grass allergens (64) as well as GAD peptides (65). There were differences in the percentage expression of individual V $\beta$ TCR families between these strains. Total V $\beta 8$ TCR expression was equivalent in DQ6 $\alpha \beta$, DQ6 $\beta / 8 \alpha \beta$, and $\mathrm{DQ} 8 \alpha \beta$ mice, while expression of the V $\beta 8.1$ subfamily was undetected in DQ6 $\alpha \beta$ and DQ6 $\beta / 8 \alpha \beta$ mice (Fig. 2).

$C I I$-specific proliferative response by $H L A-D Q 6 \alpha \beta$ and $D Q 6 \beta / 8 \alpha \beta$ mice. To assess the role of HLA-DQ6 molecule in the recognition and presentation of bovine CII, in vitro proliferative assays were performed. In three separate assays, LNCs derived from bovine CII-primed DQ6 $\alpha \beta$ and DQ6 $\beta / 8 \alpha \beta$ mice were challenged with bovine CII. One representative proliferative assay is depicted in Fig. 3. The DQ6 $\alpha \beta$ LNCs did not respond to bovine CII. On the other hand, DQ6 $\beta / 8 \alpha \beta$ LNCs did mount a significant CII-specific proliferative response, equivalent to DQ8 $\alpha \beta$ transgenic LNCs.

The proliferative response induced by bovine CII in DQ6 $\beta /$ $8 \alpha \beta$ mice was DQ8-specific and driven by CD4+ cells, as shown in Fig. 4. Blocking of either DQ or CD4 molecules inhibited CII-specific proliferation, while anti-DQ63, anti$\mathrm{H}-2 \mathrm{~A}_{\alpha}{ }^{\mathrm{b}}$, anti-H-2 $\mathrm{E}_{\beta}{ }^{\mathrm{b}}$, and anti-CD8 $\mathrm{mAb}$ had no effect on the CII-induced response. Therefore, although the DQ6 molecule did not adequately recognize and/or present CII, its presence did not inhibit the ability of DQ8 molecules to induce a CIIspecific cell-mediated response of DQ6 $\beta / 8 \alpha \beta$ mice in vitro.

Clinical parameters of CIA in HLA-DQ6 $\alpha \beta$ and HLA$D Q 6 \beta / 8 \alpha \beta$ mice. Three independent experiments pooled in

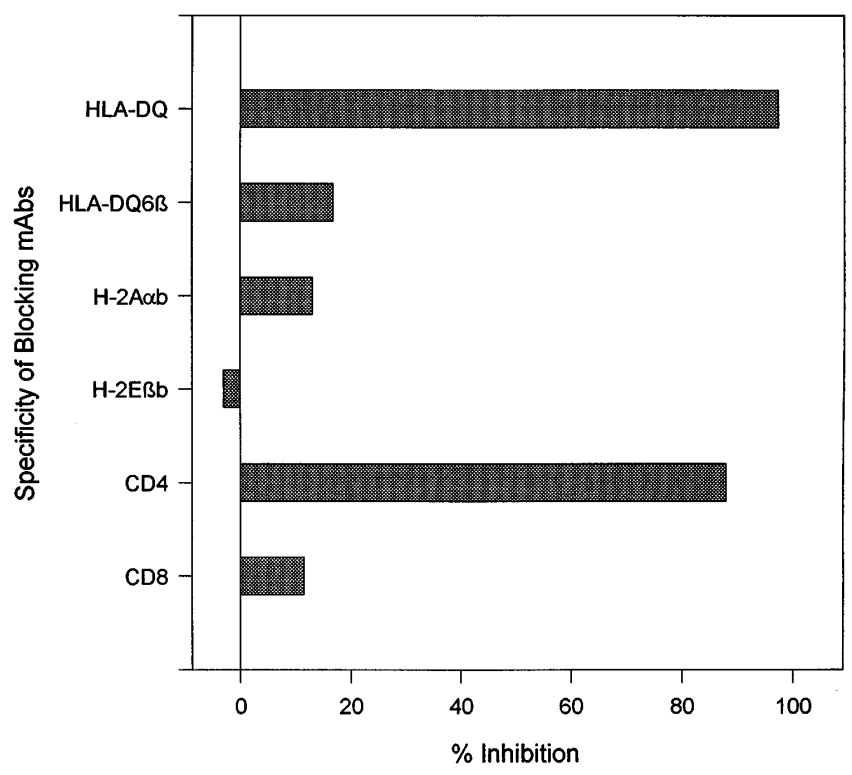

Figure 4. Inhibition of CII-specific HLA-DQ6 $\beta / 8 \alpha \beta$ LNCs proliferative response. Purified LNCs from three bovine CII-primed DQ6 $\beta$ / $8 \alpha \beta$ mice were cocultured with bovine $\mathrm{CII}$ and $\mathrm{mAb}$ specific for the $\mathrm{DQ} \alpha, \mathrm{DQ} 6 \beta, \mathrm{H}-2 \mathrm{~A}_{\alpha}{ }^{\mathrm{b}}, \mathrm{H}-2 \mathrm{E}_{\beta}{ }^{\mathrm{b}}, \mathrm{CD} 4$, or CD8 molecules, or an irrelevant isotype-matched control as described in Methods. The percent inhibition of bovine CII response was calculated by comparison with the proliferation of the LNCs in the irrelevant control mAb culture. The results displayed are representative of two independent blocking experiments. 
Table II. Incidence, Onset, and Severity of Arthritis in CII-Immunized HLA-DQ6 $\beta$ Mice

\begin{tabular}{lcccc}
\hline \multicolumn{1}{c}{ Mouse strain } & \multicolumn{2}{c}{ Incidence of arthritis } & & \\
\cline { 2 - 3 } & $\begin{array}{c}\text { Arthritic/ } \\
\text { total mice }\end{array}$ & $\begin{array}{c}\text { Percent } \\
\text { arthritic }\end{array}$ & $\begin{array}{c}\text { Day of } \\
\text { onset } \pm \text { SE }\end{array}$ & $\begin{array}{c}\text { Peak arthritic } \\
\text { severity } \pm \text { SE }\end{array}$ \\
\hline HLA-DQ6 $\alpha \beta$ & $3 / 21^{\ddagger}$ & $14.3^{\ddagger}$ & $41 \pm 11$ & $3.0 \pm 0.3$ \\
HLA-DQ6 $\alpha \beta$ neg & $0 / 14$ & 0.0 & - & - \\
A $\beta$ B0 & $0 / 5$ & 0.0 & - & - \\
B10.T(6R) & $18 / 19^{\ddagger}$ & $94.7^{\ddagger}$ & $42 \pm 4$ & $6.8 \pm 1.1$ \\
\hline
\end{tabular}

CIA was induced as described in Methods. Mice were monitored for 12 wk for the onset and severity of disease. Only arthritic mice were included in the computation of arthritic severity, with potential scores of 0-12/mouse. ${ }^{\ddagger} P<0.01$.

Table II, containing a total of 21 DQ6 $\alpha \beta, 14$ DQ6 $\alpha \beta$ negative littermates, and 19 CIA-susceptible B10.T(6R) $\left(\mathrm{H}-2 \mathrm{~A}^{\mathrm{q}}\right)$ mice were immunized with bovine $\mathrm{CII}$ in CFA on day 0 and boosted with bovine $\mathrm{CII}$ in IFA $28 \mathrm{~d}$ later. The DQ6 $\alpha \beta$ mice were resistant to CIA showing a mean incidence of $14 \%$ compared with 95\% incidence in CIA-prototypic B10.T $(6 \mathrm{R})$ mice $(P<0.01)$. Only one of the three DQ6 $\alpha \beta$ mice displaying disease exhibited severe arthritis, and the mean severity of arthritic DQ6 $\alpha \beta$ was considerably less than that of the B10.T(6R) group.

To determine the effect of the expression of HLA-DQ6 molecules on HLA-DQ8-mediated arthritis, CIA was induced in cohorts of DQ6 $\beta / 8 \alpha \beta$ and DQ6 $\beta / 8 \alpha \beta$-negative littermates, as well as in DQ8 $\alpha \beta$ and B10.T(6R) mice. The pooled results of three separate experiments are shown in Table III. The mean incidence of arthritis in the DQ6 $\beta / 8 \alpha \beta$ mice was slightly reduced compared with the DQ8 $\alpha \beta$ and B10.T(6R) groups. The day of onset was delayed in DQ6 $\beta / 8 \alpha \beta$ mice by an average of $6 \mathrm{~d}$ relative to DQ $8 \alpha \beta$ mice. The severity of disease was significantly reduced in DQ6 $\beta / 8 \alpha \beta$ when compared with DQ8 $\alpha \beta$ mice with $(P<0.05)$. Although the presence of DQ6 molecules had no effect on in vitro CII presentation, it did cause a reduction in the incidence and severity of disease.

Anti-CII antibody levels in HLA-DQ6 $\alpha \beta$ and $H L A-D Q 6 \beta /$ $8 \alpha \beta$ mice after CII immunization. Anti-CII IgG levels were determined in the sera of DQ6 $\alpha \beta$ on days 35 and 84 after bovine CII immunization to determine the influence of the HLADQ6 molecule on the humoral CII response. An anti-bovine CII-specific IgG response was detected in DQ6 $\alpha \beta$ mice (Table IV). This response, however, was significantly lower than the levels of anti-bovine CII IgG present in B10.T(6R) mice $(P<0.01$ at day 35 and $P<0.10$ at day 84$)$. Immunization of DQ6 $\alpha \beta$ mice with heterologous (bovine) CII also induced anti-self (mouse) CII-specific antibodies. The anti-mouse CII $\mathrm{IgG}$ response was also significantly less in B10.T(6R)mice $(P<$ $0.01)$.

To assess the effect of expression of HLA-DQ6 in conjunction with HLA-DQ8 on the strong DQ8-induced anti-CII IgG response, anti-CII levels were also measured in DQ6 $\beta / 8 \alpha \beta$ mice. Elevated levels of anti-bovine CII IgG were detected in DQ6 $\beta / 8 \alpha \beta$ mice at both time points (Table IV). These levels, however, were significantly lower than antibovine CII levels in the DQ8 $\alpha \beta$ and B10.T(6R) groups $(P<0.02$ and $P<0.10$, respectively). Immunization of $\mathrm{DQ} 6 \beta / 8 \alpha \beta$ mice with heterologous CII also induced anti-mouse CII specific antibodies.
Table III. Incidence, Onset, and Severity of Arthritis in CII-Immunized HLA-DQ6 $\beta / 8 \alpha \beta$ Mice

\begin{tabular}{|c|c|c|c|c|}
\hline \multirow[b]{2}{*}{ Mouse strain } & \multicolumn{2}{|c|}{ Incidence of arthritis } & \multirow[b]{2}{*}{$\begin{array}{c}\text { Day of } \\
\text { onset } \pm S E\end{array}$} & \multirow[b]{2}{*}{$\begin{array}{l}\text { Peak arthritic } \\
\text { severity } \pm \text { SE }\end{array}$} \\
\hline & $\begin{array}{l}\text { Arthritic/ } \\
\text { total mice }\end{array}$ & $\begin{array}{l}\text { Percent } \\
\text { arthritic }\end{array}$ & & \\
\hline HLA-DQ6 $\beta / 8 \alpha \beta$ & $18 / 30$ & 60.0 & $49 \pm 6$ & $3.4 \pm 1.0^{*}$ \\
\hline HLA-DQ6 $\beta / 8 \alpha \beta$ neg & $0 / 27$ & 0.0 & - & - \\
\hline HLA-DQ8 $\alpha \beta$ & $23 / 29$ & 79.3 & $43 \pm 5$ & $6.0 \pm 0.9^{*}$ \\
\hline B10.T(6R) & $23 / 26$ & 88.5 & $47 \pm 4$ & $4.7 \pm 1.0$ \\
\hline
\end{tabular}

CIA was induced as described in Methods. Mice were monitored for 12 wk for the onset and severity of disease. Only arthritic mice were included in the computation of arthritic severity, with potential scores of $0-12 /$ mouse. $* P<0.05$.

To determine the CII specificity of the anti-bovine CII antibodies detected in DQ6 $\alpha \beta$ and DQ6 $\beta / 8 \alpha \beta$ mice, the sera was tested against the $\mathrm{CB}$ fragments of bovine CII. As with CII-immunized DQ8 $\alpha \beta$ mice (42), the principle anti-CII IgG response in DQ6 $\alpha \beta$ and DQ6 $\beta / 8 \alpha \beta$ mice was specific for the CB10 fragment (Fig. 5). This is contrary to a predominately anti-CB11 response in $\mathrm{B} 10 . \mathrm{T}(6 \mathrm{R})$ mice. It is interesting that only $44 \%$ of the total anti-bovine CII response was directed against CB10 in DQ6 $\beta / 8 \alpha \beta$ mice while $55 \%$ was $\mathrm{CB} 10$ specific in the DQ8 group, a significant reduction $(P<0.05)$. Thus, $\sim 60 \%$ of the reduction of the anti-bovine $\mathrm{CII} \mathrm{IgG}$ response in DQ6 $\beta / 8 \alpha \beta$ relative to $\mathrm{DQ} 8 \alpha \beta$ mice was due to a diminished anti-CB10 antibody.

\section{Discussion}

The DQ6 $\alpha \beta$ mice were resistant to arthritis, with only 3 of the 21 mice immunized with bovine CII developing disease ( 2 mild/ 1 severe). The HLA-DQ6 gene is in linkage disequilibrium with HLA-DR2. We have shown that expression of an HLA-

Table IV. Anti-CII Antibody Levels in HLA-DQ6 $\alpha \beta$, $H L A-D Q 6 \beta / 8 \alpha \beta$, and $H L A-D Q 8 \alpha \beta$ Transgenic Mice

\begin{tabular}{|c|c|c|c|c|}
\hline \multirow[b]{2}{*}{ Mouse strain } & \multicolumn{2}{|c|}{$\begin{array}{l}\text { Anti-bovine CII IgG } \\
(\mathrm{AU} / \mathrm{ml})\end{array}$} & \multicolumn{2}{|c|}{$\begin{array}{c}\text { Anti-mouse CII IgG } \\
(\mathrm{AU} / \mathrm{ml})\end{array}$} \\
\hline & day 35 & day 84 & day 35 & day 84 \\
\hline HLA-DQ6 $\alpha \beta$ & $41 \pm 31^{\ddagger}$ & $110 \pm 23^{\S}$ & $36 \pm 25^{\|}$ & $60 \pm 13^{\mathbb{I}}$ \\
\hline HLA-DQ6 $\alpha \beta$ neg & $0 \pm 0$ & $2 \pm 2$ & $0 \pm 0$ & $6 \pm 5$ \\
\hline B10.T(6R) & $136 \pm 19^{\ddagger}$ & $170 \pm 26^{\S}$ & $160 \pm 26 \|$ & $144 \pm 21^{\mathscr{I}}$ \\
\hline HLA-DQ6 $\beta / 8 \alpha \beta$ & $136 \pm 22 * *$ 竍 & $106 \pm 17^{\S \S\|\|}$ & $52 \pm 4^{9 \pi}$ & $130 \pm 23 * * *$ \\
\hline HLA-DQ6 $\beta / 8 \alpha \beta$ neg & $5 \pm 3$ & $2 \pm 0$ & $1 \pm 0$ & $3 \pm 0$ \\
\hline HLA-DQ $8 \alpha \beta$ & $210 \pm 22^{\ddagger \ddagger}$ & $160 \pm 23^{\S \S}$ & $75 \pm 7$ & $153 \pm 17$ \\
\hline B10.T(6R) & $196 \pm 26^{* * *}$ & $174 \pm 16^{\|\|}$ & $109 \pm 17^{\mathscr{I} \Psi}$ & $269 \pm 25 * * *$ \\
\hline
\end{tabular}

Anti-CII antibody levels were determined in individual sera obtained from 14 DQ6 $\alpha$, 9 DQ6 $\alpha \beta, 20$ DQ6 $\beta / 8 \alpha \beta, 20$ DQ6 $\beta / 8 \alpha \beta$ neg, 21 DQ $8 \alpha \beta$, and 30 B10.T(6R) (12 assayed with DQ6 $\alpha \beta$, and 18 assayed with DQ6 $\beta$ / $8 \alpha \beta)$ bovine CII immunized mice as described in Methods. AU = antibody units, the level of anti-CII IgG in sample sera standardized against high titer control serum, arbitrarily determined to be equal to $100 \mathrm{AU} /$

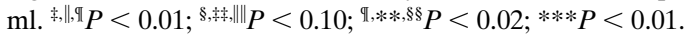




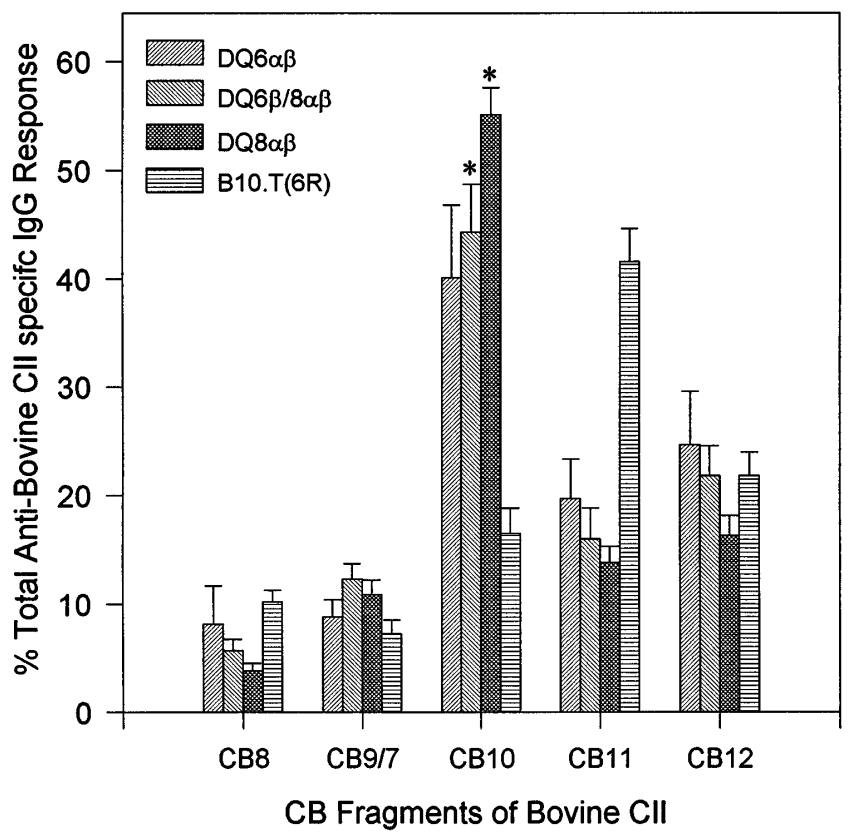

Figure 5. Specificity of anti-CII antibody responses in HLA-DQ6 $\alpha \beta$ and HLA-DQ6 $\beta / 8 \alpha \beta$ mice. The levels of anti-bovine CII IgG specific for $\mathrm{CB}$ fragments of bovine CII were determined by ELISA on sera collected $35 \mathrm{~d}$ after CII immunization of DQ6 $\alpha \beta$, DQ6 $\beta / 8 \alpha \beta$, DQ8 $\alpha \beta$, and B10.T(6R) mice. The percent of total anti-CII response was calculated by the following equation: $(1-$ [OD of anti-CB specific response/OD of total anti-bovine CII response]) $\times 100$. $* P<$ 0.05 .

DRB1*1502 (DR2) transgene can mediate protection to CIA (66). Taken together, these results may explain why HLADQ6/DR2 individuals are not predisposed to RA. We predicted that double-transgenic DQ6/DR2 mice would be completely resistant to CIA. There was a dichotomy between the DQ6 $\alpha \beta$ humoral and cell-mediated CII-specific responses. The DQ6 $\alpha \beta$ T cells failed to proliferate when challenged with bovine CII, suggesting an inability of DQ6 either to recognize or present bovine CII-derived peptides. DQ6 $\alpha \beta$ mice, however, did produce both heterologous and self CII-specific IgG. Therefore, even though DQ6 $\alpha \beta$ B cells were stimulated by bovine CII, the essential contribution of T cells necessary to induce arthritis was lacking in DQ6 $\alpha \beta$ mice.

This finding would suggest that allelic differences between DQ6 and DQ8 molecules may result in a qualitative difference in the recognition or presentation of bovine CII. One possibility is that the presence of the DQ6 molecule may result in active deletion of $\mathrm{T}$ cells necessary for pathogenesis. This deletion may be mediated through the DQ6-induced deletion of one or more V $\beta$ TCR families. It would be of interest to determine whether deletion of the V $\beta$ 8.1 TCR subgroup in DQ6 $\alpha \beta$ mice plays a role in CIA resistance. A more plausible explanation for the resistance to arthritis in DQ6 $\alpha \beta$ mice is that, while DQ8 molecules are able to recognize and present one or more arthritogenic epitope(s) of bovine CII, resulting in both humoral and cell-mediated CII-specific responses and disease, DQ6 is incapable of recognizing or presenting epitopes critical for arthritis. Thus, the expression of the DQ6 molecule would achieve resistance through a neutral or passive mechanism.
The epitope mapping of DQ6 and DQ8 transgenic mice with type II collagen is currently underway, and may be insightful as to the arthritogenic epitopes of CII.

The majority of humans are not homozygous at the HLA-DQ loci. Thus, many individuals express both a DQ allele associated with predisposition to disease, and a second allele associated with resistance. We have recreated this situation in this study. Our findings are similar to human studies, which have shown lesser severity of RA in heterozygous individuals of an RA-susceptible and nonsusceptible haplotype (67-69). The double-transgenic mice are an excellent tool with which to investigate the role of the polymorphic differences in DQ in susceptibility to RA, not only of CII, as described here, but also of other putative autoantigens such as proteoglycan or heat-shock proteins. These findings suggest that HLA-DQ polymorphism may play an important role in predisposition to human RA. In human RA, DQ4, 7, 8, and 9 are in linkage disequilibrium with the susceptible DRB1 alleles. All of these molecules contain an identical P1 pocket that could present an arthritogenic epitope in contrast to the nonassociated alleles, such as DQ6. Our findings suggest that the DQ $\alpha$ chain does not play a major role. We are currently generating $\mathrm{DQ} 8 \beta / 6 \alpha$ transgenic mice to determine whether disease is specific to DQ8 $\alpha \beta$.

On the basis of our findings so far, we propose the following model to explain how the DQ and DR genes play a role in CIA, and by deduction, human RA. The HLA class II genes expressed in the mouse in the absence of endogenous class II, shape the CD4 T cell repertoire in these mice. The mouse TCR can now interact with HLA class II + peptide in the periphery similar to T cells in the human. The DQ8 molecule presents an arthritogenic CII peptide, while the DQ6 molecule does not. Thus, the resistance of DQ6 is passive. We have previously reported that the DR2 molecule can downregulate CIA by generating a self peptide, contributing to negative selection of an autoreactive T cell (66). In human RA, presentation of DRB1 HV3-derived peptide by the DQ molecules may shape the T cell repertoire (70). For example, the DRB1*0401 (QKRAA) will positively select a self-reactive $\mathrm{T}$ cell, while DRB1*0402 (DERAA) will negatively select the $\mathrm{T}$ cell. In the periphery, DQ presentation of infectious antigens will expand the autoreactive $T$ cells to initiate the inflammatory disease. In addition, the DR molecules may present heat-shock protein antigens to augment the disease (71). Thus, RA predisposition and susceptibility is probably mediated by interaction of DQ/DR molecules. We are currently generating double-transgenic DQ/DR mice that will further simulate a human haplotype and reveal how DQ/DR interaction may play a role in the disease process. This humanized CIA model can potentially unravel many intriguing mysteries of how HLA class II molecules predispose individuals to RA, what may be the trigger for the onset of the disease, what determines severity, and, in the long term, potential insight for therapy.

\section{Acknowledgments}

The authors thank Dr. Hidetoshi Inoko for the HLA-DQ6 $\alpha$ and $\beta$ cosmids, Dr. Jack Strominger for the HLA DQ8 cosmids, and Dr. Chris Benoist for the $A \beta 0$ mice. We are indebted to Dr. Jeanine Baisch for generation of the DQ.A $\beta 0$ mice, Julie Hanson and the animal care technicians for the breeding and care of the mice, Michelle Smart for technical assistance, and Mary Brandt for secretarial assistance. 
These studies were supported by National Institutes of Health grants AI 14764 and AR 30752. M.M. Griffiths is supported by research funds from the Department of Veteran's Affairs.

\section{References}

1. Goldstein, R., and F.C. Arnett. 1987. The genetics of rheumatic disease in man. Rheum. Dis. Clin. N. Am. 13:487-510.

2. Nepom, G.T. 1989. Determinants of genetic susceptibility in HLA-associated autoimmune disease. Clin. Immunol. Immunopathol. 53(2 Pt 2):S53-S62.

3. Torfs, C.P., M.C. King, B. Huey, J. Malmgren, and F.C. Grumet. 1986. Genetic interrelationship between insulin-dependent diabetes mellitus, the autoimmune thyroid diseases, and rheumatoid arthritis. Am. J. Hum. Genet. 38: $170-187$

4. Chaplin, D.D., and M.E. Kemp. 1988. The major histocompatibility complex and autoimmunity. Year. Immunol. 3:179-198.

5. Badenhoop, K. 1990. Immunogenetic markers for autoimmune diseases of the endocrine system. Klin. Wochenschr. 68(Suppl. 21):10-14.

6. Skanes, V.M., J. Barnard, N. Farid, W.H. Marshall, L. Murphy, D. Rideout, R. Taylor, G. Xidos, and B. Larsen. 1986. Class III alleles and high-risk MHC haplotypes in type I diabetes mellitus, Graves' disease and Hashimoto's thyroiditis. Mol. Biol. Med. 3:143-157.

7. Farid, N.R., and C. Thompson. 1986. HLA and autoimmune endocrine disease 1985. Mol. Biol. Med. 3:85-97.

8. Arnett, F.C., and J.D. Reveille. 1992. Genetics of systemic lupus erythematosus. Rheum. Dis. Clin. North Am. 18:865-892.

9. Christiansen, F.T., W.J. Zhang, M. Griffiths, S.A. Mallal, and R.L. Dawkins. 1991. Major histocompatibility complex (MHC) complement deficiency, ancestral haplotypes and systemic lupus erythematosus (SLE): C4 deficiency explains some but not all of the influence of the MHC. J. Rheumatol. 18:13501358.

10. Skarsvag, S., K.E. Hansen, A. Holst, and T. Moen. 1992. Distribution of HLA class II alleles among Scandinavian patients with systemic lupus erythematosus (SLE): an increased risk of SLE among non[DRB1*03,DQA1*0501, DQB1*0201] class II homozygotes? Tissue Antigens. 40:128-133.

11. Arnett, F.C., W.B. Bias, and J.D. Reveille. 1989. Genetic studies in Sjogren's syndrome and systemic lupus erythematosus. J. Autoimmun. 2:403-413.

12. Oksenberg, J.R., A.B. Begovich, H.A. Erlich, and L. Steinman. 1993. Genetic factors in multiple sclerosis. JAMA. 270:2362-2369.

13. Maclaren, N.K., and W.J. Riley. 1986. Inherited susceptibility to autoimmune Addison's disease is linked to human leukocyte antigens-DR3 and/or DR4, except when associated with type I autoimmune polyglandular syndrome. J. Clin. Endocrinol. Metab. 62:455-459.

14. Wilson, C., A. Ebringer, K. Ahmadi, J. Wrigglesworth, H. Tiwana, M. Fielder, A. Binder, C. Ettelaie, P. Cunningham, C. Joannou, and S. Bansal. 1995. Shared amino acid sequences between major histocompatibility complex class II glycoproteins, type XI collagen and Proteus mirabilis in rheumatoid arthritis. Ann. Rheum. Dis. 54:216-220.

15. Zanelli, E., C.J. Krco, J.M. Baisch, S. Cheng, and C.S. David. 1996. Immune response of HLA-DQ8 transgenic mice to peptides from the third hypervariable region of HLA-DRB1 correlates with predisposition to rheumatoid arthritis. Proc. Natl. Acad. Sci. USA. 93:1814-1819.

16. Vogt, A.B., H. Kropshofer, H. Kalbacher, M. Kalbus, H.G. Rammensee, J.E. Coligan, and R. Martin. 1994. Ligand motifs of HLA-DRB5*0101 and DRB1*1501 molecules delineated from self-peptides. J. Immunol. 153: $1665-1673$.

17. Chicz, R.M., W.S. Lane, R.A. Robinson, M. Trucco, J.L. Strominger, and J.C. Gorga. 1994. Self-peptides bound to the type I diabetes associated class II MHC molecules HLA-DQ1 and HLA-DO8. Int. Immunol. 6:1639-1649.

18. Nepom, G.T., and H. Erlich. 1991. MHC class-II molecules and autoimmunity. Annu. Rev. Immunol. 9:493-525.

19. Wordsworth, B.P., J.S. Lanchbury, L.I. Sakkas, K.I. Welsh, G.S. Panayi, and J.I. Bell. 1989. HLA-DR4 subtype frequencies in rheumatoid arthritis indicate that DRB1 is the major susceptibility locus within the HLA class II region. Proc. Natl. Acad. Sci. USA. 86:10049-10053.

20. Ollier, W., and W. Thomson. 1992. Population genetics of rheumatoid arthritis. Rheum. Dis. Clin. North Am. 18:741-759.

21. Gregersen, P.K., M. Shen, Q.L. Song, P. Merryman, S. Degar, T. Seki, J. Maccari, D. Goldberg, H. Murphy, J. Schwenzer, et al. 1986. Molecular diversity of HLA-DR4 haplotypes. Proc. Natl. Acad. Sci. USA. 83:2642-2646.

22. Gregersen, P.K., J. Silver, and R.J. Winchester. 1987. The shared epitope hypothesis. An approach to understanding the molecular genetics of susceptibility to rheumatoid arthritis. Arthritis Rheum. 30:1205-1209.

23. Winchester, R., E. Dwyer, and S. Rose. 1992. The genetic basis of rheumatoid arthritis. The shared epitope hypothesis. Rheum. Dis. Clin. North Am. 18:761-783

24. Willkens, R.F., G.T. Nepom, C.R. Marks, J.W. Nettles, and B.S. Nepom. 1991. Association of HLA-Dw16 with rheumatoid arthritis in Yakima Indians. Further evidence for the "shared epitope" hypothesis. Arthritis Rheum. 34:43-47.
25. Yelamos, J., J.R. Garcia-Lozano, I. Moreno, I. Aguilera, M.F. Gonzalez, A. Garcia, A. Nunez-Roldan, and B. Sanchez. 1993. Association of HLA-DR4Dw15 (DRB1*0405) and DR10 with rheumatoid arthritis in a Spanish population. Arthritis Rheum. 36:811-814.

26. Sattar, M.A., M. al-Saffar, R.T. Guindi, T.N. Sugathan, and K. Behbehani. 1990. Association between HLA-DR antigens and rheumatoid arthritis in Arabs. Ann. Rheum. Dis. 49:147-149.

27. Begovich, A.B., G.R. McClure, V.C. Suraj, R.C. Helmuth, N. Fildes, T.L. Bugawan, H.A. Erlich, and W. Klitz. 1992. Polymorphism, recombination, and linkage disequilibrium within the HLA class II region. J. Immunol. 148: 249-258.

28. Harley, J.B., M. Reichlin, F.C. Arnett, E.L. Alexander, W.B. Bias, and T.T. Provost. 1986. Gene interaction at HLA-DQ enhances autoantibody production in primary Sjogren's syndrome. Science (Wash. DC). 232:1145-1147.

29. Bell, J., L. Rassenti, S. Smoot, K. Smith, C. Newby, R. Hohlfeld, K. Toyka, H. McDevitt, and L. Steinman. 1986. HLA-DQ beta-chain polymorphism linked to myasthenia gravis. Lancet. 1:1058-1060.

30. Todd, J.A., J.I. Bell, and H.O. McDevitt. 1987. HLA-DQ beta gene contributes to susceptibility and resistance to insulin-dependent diabetes mellitus. Nature (Lond.). 329:599-604.

31. Baisch, J.M., T. Weeks, R. Giles, M. Hoover, P. Stastny, and J.D. Capra. 1990. Analysis of HLA-DQ genotypes and susceptibility in insulin-dependent diabetes mellitus. N. Eng. J. Med. 322:1836-1841.

32. Singal, D.P., M. D'Souza, B. Reid, W.G. Bensen, Y.B. Kassam, and J.D. Adachi. 1987. HLA-DQ beta-chain polymorphism in HLA-DR4 haplotypes associated with rheumatoid arthritis. Lancet. 2:1118-1120.

33. Lanchbury, J.S., L.I. Sakkas, S.G. Marsh, J.G. Bodmer, K.I. Welsh, and G.S. Panayi. 1989. HLA-DQ beta 3.1 allele is a determinant of susceptibility to DR4-associated rheumatoid arthritis. Hum. Immunol. 26:59-71.

34. Taneja, V., N.K. Mehra, A.N. Chandershekaran, R.K. Ahuja, Y.N. Singh, and A.N. Malaviya. 1992. HLA-DR4-DQw8, but not DR4-DQw7 haplotypes, occur in Indian patients with rheumatoid arthritis. Rheumatol. Int. 11: 251-255.

35. Stuart, J.M., A.S. Townes, and A.H. Kang. 1984. Collagen autoimmune arthritis. Annu. Rev. Immunol. 2:199-218.

36. Stuart, J.M., E.H. Huffstutter, A.S. Townes, and A.H. Kang. 1983. Incidence and specificity of antibodies to types I, II, III, IV, and V collagen in rheumatoid arthritis and other rheumatic diseases as measures by 125I-radioimmunoassay. Arthritis Rheum. 26:832-840.

37. Trentham, D.E. 1982. Collagen arthritis as a relevant model for rheumatoid arthritis. Arthritis Rheum. 25:911-916.

38. Trentham, D.E., G.M. Kammer, W.J. McCune, and J.R. David. 1981. Autoimmunity to collagen: a shared feature of psoriatic and rheumatoid arthritis. Arthritis Rheum. 24:1363-1369.

39. Trentham, D.E., A.S. Townes, and A.H. Kang. 1977. Autoimmunity to type II collagen: an experimental model of arthritis. J. Exp. Med. 146:857-868.

40. Yoo, T.J., S.Y. Kim, J.M. Stuart, R.A. Floyd, G.A. Olson, M.A. Cremer, and A.H. Kang. 1988. Induction of arthritis in monkeys by immunization with type II collagen. J. Exp. Med. 168:777-782.

41. Wooley, P.H., H.S. Luthra, J.M. Stuart, and C.S. David. 1981. Type II collagen-induced arthritis in mice. I. Major histocompatibility complex (I region) linkage and antibody correlates. J. Exp. Med. 154:688-700.

42. Nabozny, G.H., J.M. Baisch, S. Cheng, D. Cosgrove, M.M. Griffiths, H.S. Luthra, and C.S. David. 1996. HLA-DQ8 transgenic mice are highly susceptible to collagen-induced arthritis: a novel model for human polyarthritis. $J$. Exp. Med. 183:27-37.

43. Wei, B.Y., J. Martin, S. Savarirayan, R. Little, and C.S. David. 1990. Transgenic mice and mutants in MHC research. I.K. Egorov and C.S. David, editors. Springer-Verlag, Berlin, Heidelberg, Germany. 237-246.

44. Okada, K., J.M. Boss, H. Prentice, T. Spies, R. Mengler, C. Auffray, J. Lillie, D. Grossberger, and J.L. Strominger. 1985. Gene organization of DC and DX subregions of the human major histocompatibility complex. Proc. Natl. Acad. Sci. USA. 82:3410-3414.

45. Zhou, P., G.D. Anderson, S. Savarirayan, H. Inoko, and C.S. David. 1991. Thymic deletion of $\mathrm{V}$ beta $11+, \mathrm{V}$ beta $5+\mathrm{T}$ cells in $\mathrm{H}-2 \mathrm{E}$ negative, HLA-DQ beta + single transgenic mice. J. Immunol. 146:854-859.

46. Cosgrove, D., D. Gray, A. Dierich, J. Kaufman, M. Lemeur, C. Benoist, and D. Mathis. 1991. Mice lacking MHC class II molecules. Cell. 66:1051-1066.

47. Giles, R.C., G. Nunez, C.K. Hurley, A. Nunez-Roldan, R. Winchester, P. Stastny, and J.D. Capra. 1983. Structural analysis of a human I-A homologue using a monoclonal antibody that recognizes an MB3-like specificity. J. Exp. Med. 157:1461-1470.

48. Lampson, L.A., and R. Levy. 1980. Two populations of Ia-like molecules on a human B cell line. J. Immunol. 125:293-299.

49. Beck, B.N., J.M. Buerstedde, C.J. Krco, A.E. Nilson, C.G. Chase, and D.J. McKean. 1986. Characterization of cell lines expressing mutant I-Ab and I-Ak molecules allows the definition of distinct serologic epitopes on A alpha and A beta polypeptides. J. Immunol. 136:2953-2961.

50. Lerner, E.A., L.A. Matis, C.A. Janeway, Jr., P.P. Jones, R.H. Schwartz, and D.B. Murphy. 1980. Monoclonal antibody against an Ir gene product? $J$. Exp. Med. 152:1085-1101.

51. Gregoire, C., N. Rebai, F. Schweisguth, A. Necker, G. Mazza, N. Au- 
phan, A. Millward, A.M. Schmitt-Verhulst, and B. Malissen. 1991. Engineered secreted T-cell receptor alpha beta heterodimers. Proc. Natl. Acad. Sci. USA. 88:8077-8081.

52. Tomonari, K., E. Lovering, and S. Spencer. 1990. Correlation between the $\mathrm{V}$ beta $4+\mathrm{CD} 8+\mathrm{T}$-cell population and the H-2d haplotype. Immunogenetics. 31:333-339.

53. Kanagawa, O., Y. Utsunomiya, J. Bill, E. Palmer, M.W. Moore, and F.R. Carbone. 1991. Conformational difference of T cell antigen receptors revealed by monoclonal antibodies to mouse $\mathrm{V}$ beta $5 \mathrm{~T}$ cell receptor for antigen determinants. J. Immunol. 147:1307-1314.

54. Acha-Orbea, H., R.M. Zinkernagel, and H. Hengartner. 1985. Cytotoxic $\mathrm{T}$ cell clone-specific monoclonal antibodies used to select clonotypic antigenspecific cytotoxic T cells. Eur. J. Immunol. 15:31-36.

55. Okada, C.Y., B. Holzmann, C. Guidos, E. Palmer, and I.L. Weissman. 1990. Characterization of a rat monoclonal antibody specific for a determinant encoded by the $\mathrm{V}$ beta 7 gene segment. Depletion of $\mathrm{V}$ beta $7+\mathrm{T}$ cells in mice with Mls-1a haplotype. J. Immunol. 144:3473-3477.

56. Staerz, U.D., H.G. Rammensee, J.D. Benedetto, and M.J. Bevan. 1985. Characterization of a murine monoclonal antibody specific for an allotypic determinant on T cell antigen receptor. J. Immunol. 134:3994-4000.

57. Haskins, K., C. Hannum, J. White, N. Roehm, R. Kubo, J. Kappler, and P. Marrack. 1984. The antigen-specific, major histocompatibility complexrestricted receptor on T cells. VI. An antibody to a receptor allotype. J. Exp. Med. 160:452-471.

58. Kappler, J.W., U. Staerz, J. White, and P.C. Marrack. 1988. Self-tolerance eliminates $\mathrm{T}$ cells specific for Mls-modified products of the major histocompatibility complex. Nature (Lond.). 332:35-40.

59. Bill, J., O. Kanagawa, D.L. Woodland, and E. Palmer. 1989. The MHC molecule I-E is necessary but not sufficient for the clonal deletion of V beta 11bearing T cells. J. Exp. Med. 169:1405-1419.

60. Liao, N.S., J. Maltzman, and D.H. Raulet. 1989. Positive selection determines $\mathrm{T}$ cell receptor V beta 14 gene usage by CD8+ T cells. J. Exp. Med. 170: $135-143$

61. Kappler, J.W., N. Roehm, and P. Marrack. 1987. T cell tolerance by clonal elimination in the thymus. Cell. 49:273-280.

62. Griffiths, M.M., E.J. Eichwald, J.H. Martin, C.B. Smith, and C.W. DeWitt. 1981. Immunogenetic control of experimental type II collage induced arthritis. Arthritis Rheum. 24:781-789.

63. Griffiths, M.M., G.H. Nabozny, J. Hanson, D.S. Harper, S. McCall, K.G. Moder, G.W. Cannon, H.S. Luthra, and C.S. David. 1994. Collagen-induced arthritis and TCRs in SWR and B10.Q mice expressing an Ek alpha transgene. $J$. Immunol. 153:2758-2768.

64. Krco, C.J., S. Chapoval, J. Harders, T. Neeno, and C.S. David. 1996 Identification of HLA-DQ restricted T cell epitopes on dust mite, grass, and weed allergens using HLA-DQ6 transgenic mice. Hum. Immunol. 49:16. (Abstr.)

65. DeSouza, N.F., E. Zanelli, B. Wilson, J.L. Strominger, S.R. Munn, and C.S. David. 1996. Definition of antigenic determinants on glutamic acid decarboxylase molecule in HLA-DQ transgenic mice. Hum. Immunol. 47:151. (Abstr.)

66. Gonzalez-Gay, M.A., E. Zanelli, S.D. Khare, C.J. Krco, P. Zhou, M.M. Griffiths, H.S. Luthra, and C.S. David. 1996. Human leukocyte antigenDRB1*1502 (DR2Dw12) transgene reduces incidence and severity of arthritis in mice. Hum. Immunol. 50:54-60.

67. Deighton, C.M., G. Cavanagh, A.S. Rigby, H.L. Lloyd, and D.J. Walker. 1993. Both inherited HLA-haplotypes are important in the predisposition to rheumatoid arthritis. Br. J. Rheumatol. 32:893-898.

68. Wordsworth, P., K.D. Pile, J.D. Buckely, J.S. Lanchbury, B. Ollier, M. Lathrop, and J.I. Bell. 1992. HLA heterozygosity contributes to susceptibility to rheumatoid arthritis. Am. J. Hum. Genet. 51:585-591.

69. Weyand, C.M., K.C. Hicok, D.L. Conn, and J.J. Goronzy. 1992. The influence of HLA-DRB1 genes on disease severity in rheumatoid arthritis. Ann. Intern. Med. 117:801-806.

70. Zanelli, E., C.J. Krco, and C.S. David. 1997. Critical residues on HLADRB1*0402 HV3 peptide for HLA-DQ8-restricted immunogenicity: implications for rheumatoid arthritis predisposition. J. Immunol. 158:3545-3551.

71. Auger, I., and J. Roudier. 1997. A function for the QKRAA amino acid motif: mediating binding of DNAJ to DNAK. Implications for the association of rheumatoid arthritis with HLA-DR4. J. Clin. Invest. 9:1818-1822. 